\title{
Acetaminophen in Children: Which Dosage, Which Route?
}

\section{Houman Hashemian}

Pediatric Growth Disorders Research Center, 17thShahrivar Hospital, Faculty of Medicine, Guilan University of Medical Sciences, Rasht, Iran

*Corresponding author: Hashemian H, Pediatric Infectologist, Pediatric Growth Disorders Research Center, 17thShahrivar Hospital, Faculty of Medicine, Guilan University of Medical Sciences, Rasht, Iran, Tel: 01313226101; E-mail: hashemian@gums.ac.ir

Received date: August 01, 2017; Accepted date: August 14, 2017; Published date: August 21, 2017

Copyright: $\odot 2017$ Hashemian H. This is an open-access article distributed under the terms of the Creative Commons Attribution License; which permits unrestricted use; distribution; and reproduction in any medium; provided the original author and source are credited.

\begin{abstract}
Fever is one of the most common symptoms among children, which worries parents and makes them go to physicians or emergency centers. One way to control the fever is to administer acetaminophen. Limited studies have been done on the dosage and route of administration of acetaminophen in children. This paper is a review of the correct use of acetaminophen in children based on existing randomized clinical trial studies and with emphasis on dosage and route of administration.
\end{abstract}

Keywords: Acetaminophen; Dose; Route

\section{Introduction}

Fever is one of the most common symptoms among children that is treated by paediatricians and other health care providers and causes concern to parents. The fever accounts for about a third of the children's medical visits [1]. Fever also has positive effects; it both alarms for infections or inflammation in the body, and stimulates the immune system and prevents the growth of certain bacteria. However, the metabolic effects of fever in children are tolerable, but in some cases, such as heart, pulmonary, metabolic and central nervous system diseases, febrile complications may make the patient worse. In addition, fever in $2 \%$ to $4 \%$ of children aged 6 months to 5 years can cause seizures. Therefore, the fever should be controlled as soon as possible in children with the above-mentioned risk factors, although in other children, control of the fever with a rectal degree temperature of $39^{\circ} \mathrm{C}$ or when the child feels uncomfortable, is recommended $[2,3]$. However, Ibuprofen is similarly or more efficacious than acetaminophen for treatment of pain and fever in adults and children and was equally safe, yet still, Acetaminophen is considered as first-line therapy for the treatment of fever and mild-to-moderate pain in infants and children according to international guidelines and recommendations [4,5]. Is the first line drug to control fever in children. The antipyretic effect of acetaminophen is dose-dependent, usually 10 to $15 \mathrm{mg} / \mathrm{kg} /$ dose every 4 hours, and is commonly used in oral and rectal routes [4-6].

It has been always controversial that which method of administration is more useful, rectal or oral. It is easier to take acetaminophen orally, and although this method has faster absorption but cannot be used for patients with vomiting. About $50 \%$ of rectal acetaminophen shortcut the liver. The absorption of acetaminophen suppositories is variable and erratic, and depends on the size of the suppository, its composition, its rate of dissolution, its location on the rectum and the contents of the rectum [6,7]. Rectal acetaminophen undergoes variable hepatic first pass metabolism. If a drug is administered in the upper part of rectum, it will be subject to the hepatic first pass effect whereas drugs in the lower part of the rectum will bypass the liver via the inferior vena cava. On average, about $50 \%$ of rectal acetaminophen will bypass the liver [8]. Because of reduced efficacy due to poor absorption and the risk of cumulative toxicity due to high or frequent doses, even American Academy of Paediatrics (AAP) has recommended that suppository be used only for oral intolerance cases like as vomiting [7-9]. In a meta-analysis, published by Goldstein et al. [10] in 2008, it was found that there was no difference in oral and rectal acetaminophen antipyretic effects [8-10].

Usual dose of acetaminophen (10 to $15 \mathrm{mg} / \mathrm{kg} /$ dose every 4 hours) is harmless and allergy to it is very rare. Limited randomized controlled trials have been done on different doses (or different routes of administration) of acetaminophen in children. In a study by Leary et al. on 38 children aged 2 to 54 months, it was found that oral acetaminophen $(60 \mathrm{mg}$ for children under one year of age and $120 \mathrm{mg}$ for children older than one year) was more effective than rectal enema with a similar dose in controlling children's fever. They recommended that acetaminophen be administered orally to control fever in children [9-11]. Scolnik et al. [9] showed no significant difference between the temperatures decrement (the maximum drop in temperature or final temperature or in temperature change during the 3 hours after administration) in children 6 months to 6 years of age treated with 15 $\mathrm{mg} / \mathrm{kg}$ oral acetaminophen and the same or double dose rectally [7-9]. Similarly, in a study by Vernon et al. on 37 children aged 3 months to 6 years, no difference in antipyretic effects of oral and rectal acetaminophen at a dose of $15 \mathrm{mg} / \mathrm{kg}$ was observed. They concluded that rectal acetaminophen is an acceptable alternative to control fever in children who cannot take it orally [10-12]. In a study by Nabulsi et al. [7] on 51 children with fever no significant differences were found among the three groups $(15 \mathrm{mg} / \mathrm{kg}$ orally, $15 \mathrm{mg} / \mathrm{kg}$ rectally, or 35 $\mathrm{mg} / \mathrm{kg}$ rectally) in the time to maximum antipyresis, time to fever reduction by $1^{\circ} \mathrm{C}$ or the mean hourly temperature from baseline to 6 hours following dose administration. Hypothermia (temperature $<36.5^{\circ} \mathrm{C}$ ) occurred in $11(21.6 \%)$ subjects, with the highest proportion being in the rectal high-dose group. They suggested that the usual dose $(15 \mathrm{mg} / \mathrm{kg})$ of rectal acetaminophen should be used in cases where oral administration is not possible such as vomiting and, considering the probability of hypothermia, administration of high doses of rectal acetaminophen should be prescribed with caution [6,7]. In our triple blind randomized clinical trial study on 76 children aged 6 months to 6 years with a high rectal temperature of 39 degrees Celsius, we compared antipyretic effects of rectal acetaminophen with two different doses of $15 \mathrm{mg} / \mathrm{kg}$ and $30 \mathrm{mg} / \mathrm{kg}$ after 1 and 3 hours after 
Citation: Hashemian H (2017) Acetaminophen in Children: Which Dosage, Which Route?. J Infect Dis Med 2: 113. doi:

Page 2 of 2

administration. There was no difference in mean temperature and its changes at one hour and 3 hours after administration of the drug, although after 3 hours, the number of patients who had at least $2^{\circ} \mathrm{C}$ decreases was significantly higher in the group who had taken high dose of rectal acetaminophen $(30 \mathrm{mg} / \mathrm{kg}$ ). No complications of acetaminophen were observed in the patients [11-13]. In other words, high dose acetaminophen may reduce fever for longer time. Of course, it is important that the total daily dose of administered acetaminophen should not be exceeded the maximum allowed dose. This finding is also confirmed in Temple et al. study in which the administration of high dose acetaminophen maintained its antipyretic effects longer. Although they have indicated that if the usual dose is repeated every 4 hours, there is no difference in effectiveness with high dose acetaminophen (46). However, Howell et al. [14] showed that unlike children receiving rectal acetaminophen at a dose of $40 \mathrm{mg} / \mathrm{kg}$, the majority of children treated with lower dose of rectal acetaminophen did not reach the therapeutic plasma level $(10 \mu \mathrm{g} / \mathrm{ml})$ [12-14].

\section{Conclusion}

Based on what is mentioned, it can be concluded that in order to control children's fever, acetaminophen may be given orally at a usual dose (10 to $15 \mathrm{mg} / \mathrm{kg}$, every 4 hours) and rectal acetaminophen should be reserved for those children who cannot take oral medication (such as vomiting). In case of using high dose of rectal acetaminophen (30 $\mathrm{mg} / \mathrm{kg}$ ) in children at high risk for fever, this high dose should be used just once and repeating the same doses should be avoided because more efficacies has not been proven and the risk of increased cumulative doses and poisoning will be followed. It should be noted that the maximum daily-allowed dose of acetaminophen is $90 \mathrm{mg} / \mathrm{kg}$ for up to 3 consecutive days or $75 \mathrm{mg} / \mathrm{kg}$ for longer use $[3,15]$.

\section{Financial Disclosure}

There is no financial disclosure in relation to this study.

\section{References}

1. Crocetti M, Moghbeli N, Serwint J (2001) Fever phobia revisited: have parental misconceptions about fever changed in 20 years. Pediatrics 107: 1241-1246.
2. Kliegman RM, Stanton BF, St Geme JW, Schor NF (2016) Fever. In: Nelson Textbook of Pediatrics (20th edn.). Elsevier, Philadelphia. pp: 1277- 1279.

3. Section on Clinical Pharmacology and Therapeutics, Committee on Drugs, Sullivan JE, Farrar HC (2011) Fever and antipyretic use in children. Pediatrics 127: 580-587.

4. Pierce CA, Voss B (2010) Efficacy and safety of ibuprofen and acetaminophen in children and adults: A meta-analysis and qualitative review. Ann Pharmacother 44: 489-506.

5. de Martino M, Chiarugi A (2015) Recent advances in pediatric use of oral paracetamol in fever and pain management. Pain Ther 4: 149-168.

6. Temple AR, Temple BR, Kuffner EK (2013) Dosing and antipyretic efficacy of oral acetaminophen in children. Clin Ther 35: 1361-1375.

7. Nabulsi M, Tamim H, Sabra R, Mahfoud Z, Malaeb S, et al. (2005) Equal antipyretic effectiveness of oral and rectal acetaminophen: A randomized controlled trial. BMC Pediatr 5: 35.

8. Morselli PL, Franco-Morselli R, Bossi L (1980) Clinicalpharmacokinetics in newborns and infants. Age-related differences and therapeutic implications. Clin Pharmacokinet 5: 485-527.

9. Scolnik D, Kozer E, Jacobson S, Diamond S, Young NL (2002) Comparison of oral versus normal and high-dose rectal acetaminophen in the treatment of febrile children. Pediatrics 110: 553-556.

10. Goldstein LH, Berlin M, Berkovitch M, Kozer E (2008) Effectiveness of oral vs. rectal acetaminophen: a meta-analysis. Arch Pediatr Adolesc Med 162: 1042-1046.

11. Leary PM, Walker KG, van der Meulen W (1997) Antipyretic effect of oral versus rectal paracetamol [letter]. S Alr Med J 87: 1708.

12. Vernon S, Bacon C, Weightman D (1979) Rectal paracetamol in small children with fever. Arch Dis Child 54: 469-479.

13. Hashemian H, Momtazbakhsh M, Atrkar Roshan Z (2013) Comparison of high loading dose versus usual dose of rectal acetaminophen in the treatment of febrile children. Arch Pediatr Infect Dis 1: 126-130.

14. Howell TK, Patel D (2003) Plasma paracetamol concentrations after different doses of rectal paracetamol in older children: A comparison of 1 g vs. $40 \mathrm{mg} \times \mathrm{kg}-1$. Anaesthesia 58: 69-73.

15. Heard K, Bui A, Mlynarchek SL, Green JL, Bond GR, et al. (2014) Toxicity from repeated doses of acetaminophen in children: Assessment of causality and dose in reported cases. Am J Ther 21: 174-183. 